\title{
High Ergonomic Risk of Computer Work Postures Among Iranian Hospital Staff: Evidence From a Cross-Sectional Study
}

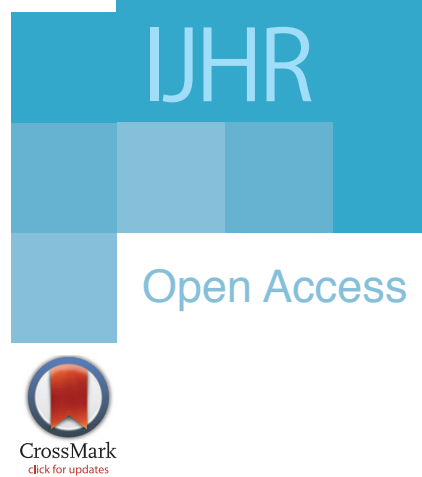

\author{
Mohammad Khandan', Zahra Arab², Alireza Koohpaei ${ }^{*}$ \\ ${ }^{1}$ Occupational Health Department, Health Faculty, Qom University of Medical Sciences, Qom, Iran. ${ }^{2}$ Department of Ergonomics, \\ University of Social Welfare and Rehabilitation Sciences, Tehran, Iran
}

First Published online March 30, 2016

\begin{abstract}
Background and Objectives: Non-ergonomic computer work has emerged as a significant cause of musculoskeletal disorders among employees of health care organizations. Given the negative impact of such disorders on quality of work life (QoWL), safety, and performance of hospital staff, there is a need to evaluate the exposure of this staff to the ergonomic risks associated with the computer-based jobs.

Methods: A sample of 150 computer user employees from two hospitals in Qom (Central Iran) was surveyed. Musculoskeletal disorder data was collected by standardized Nordic Musculoskeletal Questionnaire (NMQ). The postural states of the participants were assessed using novel ergonomic postural assessment method (NERPA) and Rapid Office Strain Assessment (ROSA). Data were summarized by descriptive statistical methods. The correlation between categorical variables was examined by chi-square test.

Findings: Among the total sample, $76.7 \%$ had administrative tasks, $20 \%$ were nurse and the rest were secretary of wards. Almost all participants (94\%) reported work-related pain at least in one of their body limbs in the past year. Pain in neck was the most frequent $(70 \%)$ musculoskeletal symptom, followed by pain in lower $(62 \%)$ and upper back (55.3\%), respectively. While most postures as assessed by NERPA were at medium level of ergonomic risk (left-hand, $74.7 \%$ and right hand, $69.3 \%$ ), significant fraction of postures were highly risky (left-hand, $24 \%$ and right hand, 29.3\%). Also ROSA recorded undesirable ergonomic score for $87.3 \%$ of the participants. Postures related to seat showed the higher frequency of undesirable scores $(86.7 \%)$, followed postures associated with the use of peripherals (44\%) and mouse/keyboard (26.7\%), respectively. The highest frequency of inappropriate ergonomic postures as identified by both methods was observed among administrative staff. Statistical test found significant correlation between risky ergonomic postures and musculoskeletal problems $(P<0.05)$.

Conclusions: Our study revealed the significant ergonomic risk associated with postural states of hospital employees working in computer workstations. Our results highlight the need for further large-scale studies to identify the extent of this occupational hazard throughout the country. Given the negative impact of musculoskeletal disorders on performance of hospital personnel and thereby patient safety, possible confirmation of widespread computer-related non-ergonomic postures will require urgent intervention.
\end{abstract}

Keywords: Ergonomics, Hospital staff, Musculoskeletal disorder, Ergonomic risk, Occupational health, Patient safety

\section{Background and Objectives}

The growing prevalence of musculoskeletal disorders among employed population has raised significant health and economic concerns. ${ }^{1,2}$ Studies have shown that musculoskeletal disorders are responsible for more than half of absenteeism in the workplace. ${ }^{3}$ The increased prevalence of musculoskeletal disorders in the workplace

*Corresponding Author: Alireza Koohpaei, Department of Ergonomics, University of Social Welfare and Rehabilitation Sciences, Tehran, Iran. Tel: +98 2537833361, Fax: +98 2537835522, Email: koohpaei19@yahoo.com stems at least partially from ergonomic factors such as repetitive motions, improper postures, and subtle repetitive tasks. ${ }^{4}$

Information technology (IT) has emerged as an integral part of current services delivery systems. Despite its revolutionary advantages for business and services provision, the rapid spread of IT use in work environment has imposed significant health challenges. ${ }^{5}$ Evidence shows that the risk of musculoskeletal disorders in employees whose job is dependent on the computer is higher than many other groups. ${ }^{6}$ Research has increasingly revealed 
that ergonomic risk factors associated with use of computer, including improper posture, prolonged and uninterrupted work, and poor design of computer workstation ${ }^{7}$ are responsible for several disorders including as eye lesions, headache, and musculoskeletal diseases such as carpal tunnel syndrome, tenosynovitis, tendinitis, and synovitis. ${ }^{7-10}$ Despite seriousness of the health problems arising from computer-based jobs, ${ }^{11,12}$ these hazards has not received adequate attention from occupational health agencies, regulatory bodies, and policy-makers usually. ${ }^{13}$ It is estimated that $12 \%$ of the worldwide workforce is active in the health sector. ${ }^{14}$ Health care organizations increasingly utilize IT in various clinical and paraclinical procedures. Examples include electronic health recording, computerized medical prescription, and barcoding, scanning, and reporting procedures. ${ }^{15}$ Therefore, the health care personnel whose job is dependent on use of computer are increasingly exposed to the risks of musculoskeletal disorders. Ergonomic injuries are considered as one of the most common health care organizations. ${ }^{16}$ The relationship between absence from work and musculoskeletal disorders among health care staff is already evident. ${ }^{17,18}$ On the other hands, the negative impact of musculoskeletal disorders among hospital staff on patient safety is well established. ${ }^{19,20}$ Thus, otherwise addressed efficiently, the computer-related ergonomic risk factors would negatively influence the quality of work life (QoWL) in the health employees, which in turn would damage the quality of care and hospital performance. ${ }^{21}$ It is therefore of significance to identify and reduce these risk factors as a part of occupational health assessment and improvement process.

Because use of IT in health organizations is relatively recent, the health and safety consideration pertaining to IT jobs is new to many employees as well as hospital administrators. To promote attention to the significance of the issue, in this study we surveyed the ergonomic risk factors among the staff of 2 sample Iranian hospitals using multiple assessment tools including and the novel ergonomic postural assessment method (NERPA) ${ }^{22}$ and Rapid Office Strain Assessment (ROSA). ${ }^{23,24}$ The implications for reducing risk of musculoskeletal disorders are discussed.

\section{Methods}

\section{Study Design and Sample}

This cross-sectional study was conducted by enrolling 150 hospital staff from among secretariats of wards, nurses, and administrative staff.

\section{Study Tools}

Musculoskeletal disorder data were collected using standardized Nordic Musculoskeletal Questionnaire (NMQ). ${ }^{25,26}$
NERPA $^{22}$ and ROSA ${ }^{24}$ were used to evaluate the extent to which the computer work postures comply with ergonomic standards. NERPA is a recently introduced approach for ergonomic evaluation and design of the workplace. In the evaluation phase of this method, the target body positions are classified into low, medium, and high risk states depending on their degree of compliance to ergonomic standards. ${ }^{22}$ We also used ROSA to identify the frequency of employees' ergonomically risky postures while working in computer workstation. ROSA method was first introduced in $2012^{24}$ to assess the risk factors associated with administrative tasks in the workplace. ROSA scores the postures of an individual when using seat, monitor/telephone, and mouse/keyboard based on their compliance with ergonomic principles. The final ROSA score ranges from 1 to 10 , where scores 1 to 4 correspond to ergonomic or "white" status and scores 5 and greater represent ergonomic risk. ${ }^{24}$

\section{Data Analysis}

Data was summarized by descriptive statistical methods. The dependence of categorical variables was tested using chi-square test. All analyses were carried out using SPSS version 20 software package.

\section{Ethical Issues}

The study was approved by the Ethical Committees of Qom University of Medical Sciences. The participants were briefed about the study objectives and their verbal consent was obtained.

\section{Results}

Table 1 describes the demographic and professional characteristics of the study sample. Of the total participants $(n=150), 85$ (56.7\%) were female, $115(76.7 \%)$ had administrative jobs, $91(60 \%)$ held a BS degree or higher, 87 (58\%) was between 20 and 35 years of age, and 76 (51\%) had less than 10 years of work experience.

Based on NMQ, 141 (94\%) of employees experienced pain at least in one body site during the last year. Pain in neck was the most frequent $(70 \%)$ musculoskeletal symptom, followed by pain at lower $(62 \%)$ and upper back (55.3\%), respectively (Table 2 ).

Table 3 presents the results of NERPA-based survey. As seen all postures have certain level of ergonomic risk. While most postures are at medium level of risk (lefthand, $74.7 \%$ and right hand, $69.3 \%$ ), significant fraction of postures are highly risky (left-hand, $24 \%$ and right hand, $29.3 \%$ ). The highest frequency of medium- and high-risk postures was observed among administrative staff. Statistical test found significant correlation between risky ergo- 
Table 1. Demographic and Professional Characteristics of the Participants

\begin{tabular}{lcc}
\hline Variable & No. & $\%$ \\
\hline Job $(\mathrm{n}=150)$ & 115 & 76.7 \\
Administrative & 30 & 20 \\
Nursing & 5 & 3.3 \\
Secretary of ward & & \\
\hline Education level $(\mathrm{n}=150)$ & 37 & 24.7 \\
Diploma and lower & 22 & 14.7 \\
Associate degree & 91 & 60.7 \\
Bachelor and higher & & \\
\hline Age $(\mathrm{y})$ ( $\mathrm{n}=150)$ & 87 & 58 \\
$20-35$ & 51 & 34 \\
$36-50$ & 12 & 8 \\
$>50$ & & 18.3 \\
\hline Work experience $(\mathrm{y})(\mathrm{n}=150)$ & 33 & 22 \\
$<10$ & 76 & 50.7 \\
$10-15$ & 18 & 12 \\
$16-20$ & & \\
\hline & & \\
\hline
\end{tabular}

Table 2. Frequency of NQM-Based Reported Musculoskeletal Pains Among Participants $(n=150)$

\begin{tabular}{|c|c|c|}
\hline Body limb & No. & $\%$ \\
\hline \multicolumn{3}{|l|}{ Ankle } \\
\hline Left & 25 & 16.7 \\
\hline Right & 25 & 16.7 \\
\hline \multicolumn{3}{|l|}{ Thigh } \\
\hline Left & 30 & 20 \\
\hline Right & 30 & 20 \\
\hline \multicolumn{3}{|l|}{ Knee } \\
\hline Left & 34 & 22.7 \\
\hline Right & 31 & 20.7 \\
\hline \multicolumn{3}{|l|}{ Wrist } \\
\hline Left & 25 & 16.7 \\
\hline Right & 50 & 33.3 \\
\hline \multicolumn{3}{|l|}{ Shoulder } \\
\hline Left & 37 & 24.7 \\
\hline Right & 49 & 32.7 \\
\hline \multicolumn{3}{|l|}{ Elbow } \\
\hline Left & 36 & 24 \\
\hline Right & 21 & 14 \\
\hline Upper back & 83 & 55.3 \\
\hline Lower back & 93 & 62 \\
\hline Neck & 105 & 70 \\
\hline
\end{tabular}

Abbreviation: NQM, Nordic Musculoskeletal Questionnaire.

nomic postures and musculoskeletal problems $(P<0.05)$.

Also ROSA recorded undesirable ergonomic score for $131(87.3 \%)$ of the participants. Postures related to seating showed the higher frequency of unfavorable scores $(86.7 \%)$, followed postures associated with the use of peripherals (44\%) and moth/keyboard (26.7\%), respectively.
Again the highest frequency of inappropriate ergonomic postures based on overall ROSA score was observed among administrative staff (68\%). Statistical test found significant correlation between employees' ergonomically unfavorable postures at computer workstation and musculoskeletal disorders $(P<0.05)$.

\section{Discussion}

Hospital work environment imposes several physical, psychological, cognitive stresses on the employees. Use of technologies such as IT in clinical procedures, while brings many advantages, imposes its own occupational health hazards. ${ }^{27}$

There is limited literature on assessment and improvement of ergonomic conditions in work station of health care organizations in the Iranian context. To help fill this gap, the present study surveyed compliance of work stations and employees' postures to the computer-related ergonomic standards in two Iranian hospitals.

With the exception of a dozen of the participants, other employees experienced pain at least in one limb due to poor posture imposed by their workstation conditions. The most frequently reported pain limbs was in neck (70\%) followed by lower (62\%) and upper (55\%) back, respectively. Previous studies have also shown similar pattern of musculoskeletal pain among administrative staff. ${ }^{27-31}$ Pain in the upper limbs has been identified as a major cause of clinical errors, ${ }^{32}$ which directly endanger patient safety. ${ }^{33}$ Therefore, urgent intervention such as redesign of the layout of the workstation should be undertaken in order in order to prevent patient safety problems.

Our results showed that all postures of the surveyed employees are subject to medium to high ergonomic risk. This observation indicates the alarming situation for the health and QoWL of the hospital staff, particularly those whose job is dependent on the use of computer. Evidence shows that managers' commitment and appropriate incentives have the potential to alleviate occupational health hazards. ${ }^{34}$ Therefore, apart from redesign of work station layout, managerial, motivational, and psychosocial contributors to ergonomic risk reduction should be emphasized.

ROSA-based results showed that more than $85 \%$ of sitting postures is not ergonomic. Some previous studies have also reported non-ergonomic sitting postures as the most frequent work-related risk factor of musculoskeletal disorders. ${ }^{35}$ It was shown that training of ergonomic principle and practice alone, even without redesign of workstation layout can significantly reduce the ergonomic risk factors and thereby the related musculoskeletal problems. ${ }^{36}$

Onishi et $\mathrm{al}^{36}$ in their study among the employees of a 
Table 3. Frequency (\%) of NERPA-Based Undesirable Postures Based on Risk Levels

\begin{tabular}{|c|c|c|c|c|}
\hline \multirow{2}{*}{ Risk Level } & \multicolumn{3}{|l|}{ Job } & \multirow{2}{*}{ Total } \\
\hline & Secretary of Ward & Nurse & Administrative & \\
\hline \multicolumn{5}{|l|}{ Low } \\
\hline Left & 0 & 0 & 0 & 0 \\
\hline Right & 0 & 0 & 0 & 0 \\
\hline \multicolumn{5}{|l|}{ Medium } \\
\hline Left & $2(1.3)$ & $24(16)$ & $86(57.3)$ & $112(74.7)$ \\
\hline Right & $3(2)$ & $21(14)$ & $80(53.3)$ & $104(69.3)$ \\
\hline \multicolumn{5}{|l|}{ High } \\
\hline Left & $3(2)$ & $6(4)$ & $29(19.3)$ & $38(24)$ \\
\hline Right & $2(1.3)$ & $9(6)$ & $35(23.3)$ & $46(29.3)$ \\
\hline
\end{tabular}

Abbreviation: NQM, novel ergonomic postural assessment method.

Japanese teaching hospital showed that females are more prone to upper limb disorders compared with males. Females were the major gender in our survey and they also comprise a majority of hospital staff in the Iranian health system. ${ }^{37}$ Therefore, female staff is the prime target group for interventions aimed at improving the ergonomic factors in health care workplaces.

In addition to inappropriate seat, the non-ergonomic use of mouse and keyboard was also found to be relatively high, particularly among the administrative staff. Training of staff for ergonomic use of these devices, using the suitable pad for mouse, use of arm support, and use of wireless mouse has proven useful in alleviating ergonomic risks of these devices. ${ }^{38}$

The rapid diffusion of IT in clinical procedures and increasing dependent of medical technologies on computer systems requires a principal and strategic approach to incorporation of IT-based systems in health care delivery. Such an approach among other factors should also address safe and ergonomic installation of the relevant computer workstations as well as recruitment and training of staff for occupationally safe operation of the computer-based medical equipment. Given the direct impact of QoWL of hospital staff on patient safety, it is recommended that observation of ergonomic principles by computer using staff be considered as a component of patient safety culture.

\section{Conclusions}

This study surveyed the ergonomic risk facing hospital staff associated with computer operation in two Iranian teaching hospitals. Almost all of the employees experienced pain at least in one limb due to poor postural state. Most reported pain sites were neck, followed by lower and upper back, respectively. All postures of the surveyed employees were subject to medium to high ergonomic risk. Administrative staff displayed the highest frequen- cy of risky postures. While, the majority of risky postures were associated with seat, a significant fraction computer work postures were also non-ergonomic. The observed situation reveals low compliance of computer workstation layout with the ergonomic standards as well as limited knowledge of the employees on ergonomically correct interaction with computer terminals. Our results recommend conduction of further studies to identify the extent of workplace hazard throughout the country. Widespread non-ergonomic postural behaviors, if confirmed in future studies, will require urgent intervention regarding its direct impact on performance of health human resources and patient safety. Based on our results and previous successful interventions, reconfiguration of computer workstation according to ergonomic principles and training computer operators are promising strategies to alleviate this occupational hazard.

\section{Abbreviations}

(NMQ): Nordic musculoskeletal questionnaire; (NERPA): novel ergonomic postural assessment method; (ROSA): rapid office strain assessment; (QoWL): quality of work life.

\section{Competing Interests}

The authors declare no competing interests.

\section{Authors' Contributions}

MK conceived, designed and supervised the study. AZ collected the data and contributed to data analysis. AK and MK were involved in data analysis, interpretation of results, and drafting the manuscript. All authors read and approved the final manuscript.

\section{Acknowledgements}

The authors would like to appreciate Vice-president for Research of Qom University of Medical Sciences for 
funding and supporting this project. The authors also thank to all hospital staff who kindly participated in this study.

\section{References}

1. Andersson GB. Epidemiological features of chronic lowback pain. Lancet. 1999;354(9178):581-585.

2. Andersen LL, Clausen T, Mortensen OS, Burr H, Holtermann A. A prospective cohort study on musculoskeletal risk factors for long-term sickness absence among healthcare workers in eldercare. Int Arch Occup Environ Health. 2012;85(6):615622. doi:10.1007/s00420-011-0709-5.

3. Ohlsson K, Attewell R, Skerfving S. Self-reported symptoms in the neck and upper limbs of female assembly workers:impact of length of employment, work pace, and selection. Scand J Work Environ Health. 1989;15(1):75-80.

4. Chobineh AR. Posture Assessment Methods in Occupational Ergonomics (Persian). Tehran: Fanavaran Publication; 2007.

5. Mirmohammadi S, Mehrparvar A, Soleimani H, Lotfi M, Akbari $\mathrm{H}$, Heidari N. Musculoskeletal disorders among video display terminal (VDT) workers comparing with other office workers (Persian). Iran Occup Health 2010;7(2):4-11.

6. Gerr F, Marcus M, Monteilh C. Epidemiology of musculoskeletal disorders among computer users:lesson learned from the role of posture and keyboard use. J Electromyogr Kinesiol. 2004;14(1):25-31.

7. Juul-Kristensen B, Søgaard K, Støyer J, Jensen C. Computer users' risk factors for developing shoulder, elbow and back symptoms. Scand J Work Environ Health. 2004;30(5):390398.

8. Voerman GE, Sandsjö L, Vollenbroek-Hutten MM, Larsman P, Kadefors R, Hermens HJ. Effects of ambulant myofeedback training and ergonomic counselling in female computer workers with work-related neck-shoulder complaints:a randomized controlled trial. Scand J Work Environ Health. 2004;30(5):390-398

9. Rurkhamet B, Nanthavanij S. Analytic and rule-based decision support tool for VDT workstation adjustment and computer accessories arrangement. J Hum Ergon. 2004;33(1-2):1-17.

10. Sweere HC. Ergonomic factors involved in optimum computer workstation design: a pragmatic design. Constant Force Technology, LLC; 2002

11. Salvage J, Rogers R, Cowell R. Nurses at risk. Nurs Times. 1998;94(33):34-35.

12. Triolo PK. Occupational health hazards of hospital staff nurses. Part II:physical, chemical, and biological stressors. AAOHN J. 1989;37(7):274-279.

13. Manyele SV, Ngonyani HA, Eliakimu E. The status of occupational safety among health service providers in hospitals in Tanzania. Tanzan $J$ Health Res.
2008;10(3):159-165.

14. Goniewicz M, Włoszczak-Szubzda A, Niemcewicz M, Witt M, Marciniak-Niemcewicz A, Jarosz MJ. Injuries caused by sharp instruments among healthcare workers-international and Polish perspectives. Ann Agric Environ Med. 2012;19(3):523-527

15. Carayon P. Handbook of Haman Factors and Ergonomics in Health Care and Patient Safety. 2nd ed. CRC Press; 2012.

16. Moving and handling in health and social care. Health and safety executive (HSE) website. http://www.hse.gov.uk/ healthservices/moving-handling.htm.

17. Agency for Healthcare Research and Quality. the Effect of Health Care Working Conditions on Patient States. Rockville, MD: AHRQ; 2003.

18. Aiken LH, Clarke SP, Cheung RB, Sloane DM, Silber JH. Educational levels of hospital nurses and surgical patient mortality. JAMA. 2003;290(12):1617-1623.

19. Geiger-Brown J, Trinkoff AM, Nielsen K, Lirtmunlikaporn S, Brady B, Vasquez El. Nurses' perception of their work environment, health, and well-being:a qualitative perspective. AAOHN J. 2004;52(1):16-22

20. Trinkoff AM, Lipscomb JA, Geiger-Brown J, Storr CL, Brady BA. Perceived physical demands and reported musculoskeletal problems in registered nurses. Am J Prev Med. 2003;24(3):270-275.

21. Menzel NN, Brooks SM, Bernard TE, Nelson A. The physical workload of nursing personnel:association with musculoskeletal discomfort. Int J Nurs Stud. 2004;41(8):859867.

22. Sanchez-Lite A, Garcia M, Domingo R, Angel Sebastian M. Novel ergonomic postural assessment method (NERPA) using product-process computer aided engineering for ergonomic workplace design. PLoS One. 2013;8(8):e72703. doi:10.1371/journal.pone.0072703.

23. Ferasati F, Sohrabi MS, Jalilian M. Evaluation of musculoskeletal disorder in VDT users with rapid office strain assessment (ROSA) method (Persian). Journal of Ergonomics. 2014;1(3):65-74.

24. Sonne M, Villalta DL, Andrews DM. Development and evaluation of an office ergonomic risk checklist: ROSA-rapid office strain assessment. Appl Ergon. 2012;43(1):98-108. doi:10.1016/j.apergo.2011.03.008.

25. Kuorinka I. Standardized Nordic questionnaires for the analysis of musculoskeletal symptoms. Appl Ergon. 1987;18:233-237.

26. Crawford JO. The Nordic Musculoskeletal Questionnaire, Occup Med. 2007; 57:300-301.

27. Janowitza IL, Gillenb M, Ryanc G, et al. Measuring the physical demands of work in hospital settings:Design and implementation of an ergonomics assessment. Appl Ergon. 2006;37:641-658. 
28. Choobineh A, Rahimi Fard H, Jahangiri M, Mahmood Khani S. Musculoskeletal injuries and their associated risk factors (Persian). Iran Occup Health. 2012;8(4):70-81.

29. Mousavifard A, Zarei F. Assessment of musculoskeletal disorders prevalence and work posture analysis of administrative personnel using with RULA, Ergo Intelligence - UEA Software and NMQ (Persian). Karaj University of Medical Sciences Journal. 2013;2(4):245-250.

30. Nadri H, Nadri A, Khanjani N, Nadri F, Jafari Roudbandi A. Survey of effective factors on the MSDs among administrative personnel in Qazvin (Persian). Health Dev J. 2013;2(2):106-116.

31. Choobineh A, Motamedzade M, Kazemi M, Moghimbeigi A, Heidari Pahlavian A. The impact of ergonomics intervention on psychosocial factors and musculoskeletal symptoms among office workers. Int J Ind Ergon. 2011;41(6):671-676. doi:10.1016/j.ergon.2011.08.007.

32. Kim lu. Ergonomics in healthcare and patient safety. $J$ Ergon. 2014;4(3):e126. doi:10.4172/2165-7556.1000e126.

33. Gurses AP, Ozok AA, Pronovost PJ. Time to accelerate integration of human factors and ergonomics in patient safety. BMJ Qual Saf. 2012;21(4):347-351. doi:10.1136/ bmjqs-2011-000421.

34. Saeed R, Qaisar F, Noor M, Noor N, Ahmad W, Javed S. Impact of management techniques on reduction of safety and health risks:comparison of public and combined military hospitals in Pakistan. J Appl Environ Biol Sci. 2014;4(4):133-
138.

35. Mirmohammadi SJ, Mehrparvar AH, Olia MB, Mirmohammadi M. Effects of training intervention on non-ergonomic positions among video display terminals (VDT) users. Work. 2012;42 (3):429-433.

36. Onishi T, Kurimoto S, Suzuki M, Imaeda T, Hirata H. Workrelated musculoskeletal disorders in the upper extremity among the staff of a Japanese university hospital. Int Arch Occup Environ Health. 2014;87(5):547-555. doi:10.1007/ s00420-013-0898-1.

37. Kasnaviye $\mathrm{MH}$, Masoumi GH, Yasinzadeh $\mathrm{M}$, Haghgoo M, Tahmasebi Khob H, Amini M. Vulnerability study of health human resources in the iranian ministry of health and medical education. Int J Hosp Res. 2014;3(4):177-182.

38. Hoe VCW, Urquhart DM, Kelsall HL, Sim MR. Ergonomic design and training for preventing work-related musculoskeletal disorders of the upper limb and neck in adults. Cochrane Database Syst Rev. 2012;(8):CD008570. doi:10.1002/14651858.CD008570.pub2.

\section{Please cite this article as:}

Khandan M, Arab Z, Koohpaei A. High ergonomic risk of computer work postures among iranian hospital staff: evidence from a cross-sectional study. Int J Hosp Res. 2016;5(1):29-34. doi:10.15171/ijhr.2016.06 